\title{
Produtor e produção histórica: a inevitável cumplicidade*
}

JOSÉ AMADO MENDES**

Resumo: $\mathrm{O}$ texto procura mostrar que nas tendências mais recentes da historiografia a pessoa do historiador, com suas vivências pessoais, com sua biografia, torna-se importante elemento para a compreensão da História que escreve.

Abstract: This paper tries to show that in recent historiographic tendencies the historian, his life, his biography, are important elements for the understanding the way he productes History.

Palavras-chave: Historiografia. Nova História. Biografia.

Key words: Historiography. New History. Biography

\section{Introdução}

Em História, como nas outras Ciências Humanas e até nas próprias ciências ditas exatas - ou experimentais -, deixamos de ter certezas absolutas, herdadas do cientismo e do positivismo oitocentistas, para passarmos a ter aproximações ou níveis de probabilidades. Como é sabido, no caso das ciências experimentais, o alerta surgiu nas primeiras décadas do nosso século, sobretudo na seqüência da teoria da relatividade, de Einstein (artigos publicados em 1905 e 1916). No caso específico das Ciências Humanas e Sociais - não tendo havido, propriamente, um Einstein ou um marco cronológico tão nítido -, a transformação foi mais lenta e difusa, mas nem por isso menos óbvia. Para isso contribuíram fatores de natureza diversa, inclusive filosófica, epistemológica, metodológica, cultural, social, etc., cujo estudo detalhado não caberia no contexto da análise que aqui me proponho efetuar. Trata-

\footnotetext{
* Palestra proferida no Programa de Pós-Graduação em História da PUCRS.

** Professor catedrático da Faculdade de Letras da Universidade de Coimbra, Portugal.
} 
se, afinal, daquilo que Lucien Febvre, já em 1941, classificou como o "drama da relatividade". Sublinhava, na altura, o autor, dirigindo-se aos alunos da "École Normale Superieure" de Paris, no início do ano letivo do referido ano: "De fato, é bem verdade que no ponto de partida de todas as concepções novas dos cientistas (ou melhor, os investigadores, os que criam, os que fazem progredir a ciência e muitas vezes se preocupam mais em agir que em fazer a teoria das suas ações) - é bem verdade que neste ponto de origem se encontra o grande drama da relatividade que veio sacudir, abalar, todo o edifício das ciências, tal como um homem da minha geração [recordo que L. Febvre nascera em 1878 e viria a falecer em 1956] o imaginava na juventude".'

Quer dizer, algumas das verdades geralmente aceitas pela História tradicional ou, se se preferir, pela velha História -, a pretensa objetividade, que a História se encontrava nos documentos, pelo que só era necessário "deixá-los falar", que a função do historiador se situava ao nível da heurística, crítica e divulgação das fontes, etc. - essas verdades, repito, estavam postas em causa, o que passou a condicionar todo o processo historiográfico ou, indo mais além, toda a história da História. Entretanto, as referidas concepções foram sendo substituídas por outras constitutivas de um novo paradigma (na acepção de Kuhn), as quais se podem sumariar assim:

a) A História não se encontra propriamente nos documentos; estes, não só escritos mas de diversos outros tipos, constituem, isso $\operatorname{sim}$, a matéria-prima com a qual se faz a História. Ou seja, as fontes, consideradas no sentido lato do termo (de testemunho, de documento/monumento, etc.) estão para a História como os materiais de construção (tijolo, pedra, ferro, vidro, madeira e outros) estão para o edifício.

b) Para que os materiais/matérias-primas se transformem em edificação/produto, é imprescindível a intervenção humana (engenheiros, arquitetos, construtores e operários). De forma análoga, também não há História - como ciência, como ramo do saber ou como "estudo cientificamente conduzido" (Lucien Febvre) - sem historiador ou investigador.

c) Conseqüentemente, o papel do historiador passou a sobressair com maior nitidez, com todas as implicações que daí derivam. Desde logo, através da íntima ligação entre o fautor da História

FEBVRE, Lucien. Combates pela história (trad. do francês). 2. ed., Lisboa: Presença, 1984 , p. $35-36$. 
e o resultado do seu labor ou, de acordo com o título que dei a este trabalho, entre o produtor e a produção histórica. Philippe Ariès, entre outros autores, chamou já a atenção para essa relação, ao afirmar: "Ou a História é um movimento elementar, inflexível e sem amizade, ou existe uma comunhão misteriosa do homem na História: a interpretação do sagrado imerso no tempo, um tempo que o seu progresso não destrói, em que todas as idades são solidárias [...]. A criação histórica é um fenômeno de natureza religiosa [...]. Qualquer coisa muito próxima da graça..."

Ora, em meu entender, ainda não se tiraram todas as ilações possíveis da revolução historiográfica que acabo de sintetizar. Mais concretamente: tendo-se chegado à conclusão - hoje geralmente aceita - de que o historiador é um elemento fulcral, não só do fazer História como da própria obra historiográfica, justificarse-á que aquele continue a ser, em certa medida, um "desconhecido", não só para o público em geral como para os próprios investigadores?

Devo acrescentar, no entanto, que alguma coisa se vai fazendo, para alterar a situação. Se me é permitido, recordo algo do que, ultimamente, se tem vindo a fazer em Portugal. Assim, enquanto Armando Luís de Carvalho Homem focou a questão num artigo intitulado precisamente "Os historiadores, esses desconhecidos" (1994), ', outros trabalhos, que têm vindo a ser publicados, fornecem também importantes contributos para o estudo da vida e obra dos que têm feito - ou continuam a fazer - da História a sua profissão. De entre alguns outros, destaco os seguintes, recentemente vindos a lume:

- Sérgio Campos Matos, Memória e Nação. Historiografia portuguesa de divulgação e nacionalismo (1846-1898), 1995."

- Bibliografia Anual de História de Portugal. Anos de 1989, 1990 e 1991, Faculdade de Letras da Universidade de Coimbra, 19921995.

- Repertório Bibliográfico da Historiografia Portuguesa. 1974-1994, Faculdade de Letras da Universidade de Coimbra/Instituto Camões, 1995.

Apud AGULHON, Maurice et al. Ensaios de ego-história. Lisboa: Ed. 70, 1989. p. 166. HOMEM, Armando Luís de Carvalho. Os historiadores, esses desconhecidos. Revista Portuguesa de História, t. 24, 1994, p. 33-53.

4 Dissertação de doutoramento, apresentada à Faculdade de Letras da Universidade de Lisboa, policopiada, 1995. 
- Luís Reis Torgal, José Amado Mendes e Fernando Catroga, História da História em Portugal. Séculos XIX-XX, Lisboa, Círculo de Leitores, 1996.

Também no Brasil, o crescente interesse pela história da História, que ultimamente se tem verificado (na linha de José Honório Rodrigues e de vários outros investigadores), por certo induzirá se já não induziu - a dedicar-se mais atenção aos próprios historiadores.

Permitam-me que sublinhe o fato - positivo, em meu entender - de, também aqui no Brasil, os estudos historiográficos começarem a focar, inclusive, o passado recente. Entre muitos outros exemplos - com que os presentes estarão, por certo, mais familiarizados que eu próprio -, recordo o contributo de Carlos Fico e Ronald Polito, A História no Brasil (1980-1989). Elementos para uma avaliação historiográfica (v. 1, com prefácio de Carlos Guilherme Mota, Ouro Preto, Ed. UFOP, 1992).

\section{O historiador: de figurante secundário a protagonista}

Como já se deu a entender, o historiador, ao exercer a sua atividade na "oficina" da História, não pode permanecer numa atitude passiva. Cabe-lhe liderar todo o processo, sob vários pontos de vista, o que, obviamente, não deixa de ter consequências ao nível da própria história que ele faz.

$\mathrm{O}$ historiador/investigador começa por enunciar um problema, formular uma questão ou expressar uma dúvida. Por vezes, formula hipóteses ou elabora modelos - o que é usual na New Economic History -, que funcionam como fios condutores e balizas, ao longo da investigação. Surge, assim, um tema a pesquisar, na expectativa de que, no final do processo, o problema tenha sido solucionado, se tenha encontrado a resposta para a questão formulada ou a dúvida possa ter sido esclarecida.

Logo, neste primeiro passo da pesquisa, destacam-se a seleção temática e a elaboração de um questionário - ainda que de forma apenas implícita -, uma e outra da competência do próprio investigador. Reside aqui uma das grandes diferenças, entre a "velha" e a "nova História". Segundo o que preconizavam os cultores da primeira, "o historiador não poderia escolher os fatos. Escolher? com que direito? em nome de que princípio? Escolher, a própria negação da obra científica...". Mas, como bem notou Lu- 
cien Febvre, "toda a História é escolha". ' Obviamente que, na escolha do tema a investigar, exercem também influência fatores relacionados com o contexto socioeconômico, político-militar, cultural, religioso, ideológico, etc. Pode dizer-se que, também em História, há modas ou, se se preferir, tendências. Isto, aliás, não deve surpreender, pois sabe-se como o historiador, freqüentemente, procura no passado resoluções para os problemas do seu tempo. Noutra prespectiva, mas com resultado análogo, pode dizer-se que o historiador projeta, no fazer História, parte das suas angústias, apreensões, receios e pontos de vista; bem como teorias podendo dizer-se que "a teoria precede a História" - e concepções sobre a evolução do homem em sociedade, isto é, sobre a própria História. É conhecida a expressão de Benedetto Croce, segundo a qual "toda a verdadeira História é História contemporânea"?

Entre muitos outros exemplos, de influências do contexto histórico sobre a própria historiografia, recordo os seguintes:

a) a obra de Karl Marx (de colaboração com Engels, no caso do Manifesto Comunista, 1848) e, posteriormente, a Revolução Russa de 1917 estimularam e/ou inspiraram a investigação sobre o movimento operário, até a atualidade;

b) a crise de 1929, por seu turno, como a maior catástrofe do sistema capitalista, até então registada, deu origem a estudos vários sobre pleno emprego (Keynes), preços (Simiand, Labrousse e muitos outros) e salários, induzindo simultaneamente o desenvolvimento da História serial (P. Chaunu);

c) no pós-Segunda Guerra Mundial, além do aparecimento da New Economic History e da História de $3^{\circ}$ nível - as mentalidades, os grupos marginais, o insólito, etc. -, estiveram em voga os estudos sobre demografia histórica (França, Grã-Bretanha, Península Ibérica, etc.), para o que não deixou de contribuir o fato de, naquele conflito, terem perdido a vida à volta de 50 milhões de pessoas;

d) em Portugal, por sua vez, recordo somente dois períodos significativos: o surto da História político-militar, eivada de nacionalismo, durante a Ditadura Militar/Estado Novo (1926-1974), por um lado, e o boom da História econômica e social, no pós-25

Febvre, op cit., p. 19.

LEFEBRE, Georges. Refléxions sur l'histoire. Paris: François Maspero, 1978, p. 139.

CROCE, Benedetto. História, chrónica e falsas memórias. Memória apresentada à Academia Pontaniana na sessão de 3 de novembro de 1912. Revista de História, n. 16, 1915, p. 308. 
de Abril de 1974. Sob uma perspectiva temática, é também elucidativo o desenvolvimento da chamada "História no feminino" - em Portugal como noutros países -, o que não se pode desligar da ação dos movimentos feministas e da crescente participação da mulher nas mais variadas esferas de atividade.

Por outro lado, a própria formação, experiência e vivências do historiador imprimem, obviamente, a sua marca à obra historiográfica. Também, neste caso, se podem referir alguns exemplos. A formação universitária - em História, em Sociologia em Economia ou em combinatórias de, por exemplo, Geografia-História, Filosofia-História ou Português-História - é um importante fator a ter em conta, no estudo e na compreensão da história da História. Essa vertente ajudará a compreender, entre outras, as características de alguns dos seguintes contributos historiográficos.

Uma geração formada nos finais do século passado e nos inícios do nosso século - como os franceses Marc Bloch, Lucien Febvre e Fernand Braudel ou o português Orlando Ribeiro - souberam lidar magistralmente com o espaço e o tempo (isto é, com os já chamados "olhos da História"), devido, em grande parte, à sua dupla formação, como historiadores-geógrafos ou geógrafoshistoriadores. Por seu turno, alguns contributos muito válidos dados à historiografia - inclusive sob o ponto de vista teóricometodológico - têm-se devido a investigadores que, originariamente, obtiveram formação acadêmica, pelo menos a nível da graduação, em áreas diferentes da História (Direito, Sociologia, Geografia, Economia, etc.). Muitos deles desempenharam um papel relevante na aproximação da História com as outras Ciências Sociais, uma das características mais importantes da Nova História. Basta lembrar, por exemplo, o impulso dado à História econômica e à Nova História econômica por economistas ou por historiadores-economistas. O próprio domínio de línguas estrangeiras, assim como o contato com centros e investigadores, de outros países - em colóquios, congressos, conferências, visitas ou estadas, de maior ou menor duração - são elementos que se refletem, de forma mais ou menos difusa, na História que cada um faz. Não é por acaso que, em Portugal - e, ao que suponho, não será caso único - a maior parte das propostas historiográficas mais inovadoras provieram, exatamente, daqueles que melhor conheceram, de forma direta ou indireta, a evolução da ciência histórica noutros quadrantes. A propósito, confessou o notável historiador francês 
Georges Duby, após ter referido a sua multifacetada experiência em diversos países:

"O que não devo eu também a essas viagens, sempre mais freqüentes, sempre mais longínquas? Se não tivesse saído da minha concha, ido para essas equipes de historiadores estrangeiros, para essas culturas exóticas, teria avançado tão longe na compreensão da formação social que escolhera observar, do seu funcionamento, das idéias que as gentes, aqui, no espaço francês, há sete ou oito séculos, tinham sobre a sua situação no universo visível e invisível?"” E acrescenta Duby, no seu contributo para a conhecida obra intitulada Ensaios de ego-história, publicada em 1987: "Lucien Febvre advertia-me, persuadia-me de que o essencial não era compulsar tudo, decifrar tudo. É impossível. Atenção: nunca se enterrar nos arquivos. Contam, antes de mais, a liberdade, o gesto largo, a amplitude da vista"."

Fator também a não menosprezar é o da empatia do historiador com o seu objeto. Tal relaciona-se não só com a seleção dos temas a investigar - ao que já me referi anteriormente - como com o próprio empenho e motivação com que se lhes dedica. Por vezes, fatos aparentemente insignificantes - ocorridos na infância, na adolescência ou na juventude - podem estar na base de certas opções profissionais e, dentro destas, de orientações de acordo com preferências, gostos ou, simplesmente, de recordações que tenham deixado marcas indeléveis.

Em suma: como já foi destacado por René Rémond, no "avant-propos" à obra Etre historien aujourd'hui (1988), "o historiador na sua elaboração e ainda mais na sua difusão de modo algum foge à Historia". ${ }^{10}$

\section{Como conhecer o historiador/produtor historiográfico?}

Como veremos entretanto (ponto 4), a análise da obra histórica pode permitir que se tirem algumas ilações acerca do referido autor. Todavia, dado que, até recentemente, o historiador tendia a "apagar-se" ante as conclusões da sua pesquisa, há que recorrer a outros meios, para vislumbrar algo mais sobre aqueles(as) que se dedicam à investigação histórica, para melhor compreendermos o

\footnotetext{
8 DUBY, Georges. O prazer do historiador. In: CHAUNU, Pierre et al. Ensaios de egohistória. Lisboa: Edições 70, 1989, p. 131.

Duby, idem.

10 RÉMOND, René. Être historien anjourd'hui. Paris: UNESCO/Erès, 1988, p. 9.
} 
resultado do seu labor. Para alcançar este desiderato, revelar-se-ão de extrema utilidade a biografia, a prosopografia e a autobiografia.

No que concerne à biografia, trata-se de um gênero que, após um considerável menosprezo a que foi votado pela Nova História - embora, em países como a Inglaterra, a biografia nunca tenha deixado de estar na ordem do dia -, encontra-se atualmente em franca reabilitação. Como já dediquei alguma atenção ao assunto noutros trabalhos," aqui pouco acrescentarei. Após um período caracterizado como que por um certo "endeusamento" das massas, de acordo com uma das características do século XX - já apelidado de "século do povo"12 - e um quase que esquecimento do indivíduo, este volta a merecer atenção, inclusive da parte da História pós-moderna.

Não se tratando, propriamente, de uma novidade - lembro, por exemplo, que Las individualidades en la Historia, já em 1985 constituíram a temática de um congresso internacional, realizado na Universidade de Navarra, em Espanha, ${ }^{13}$ enquanto Problèmes et mèthodes de la biographie, no mesmo ano, foi igualmente tema de um colóquio na Sorbonne, em Paris ${ }^{14}$-, o certo é que o assunto continua a despertar interesse redobrado, quer da parte da população, quer do lado dos investigadores.

Ao mencionado "reaparecimento" do indivíduo na História e na historiografia não são estranhos fatores político-ideológicos, entre os quais se conta o de um certo desencanto à volta de algumas das experiências revolucionárias socialistas, como fenômenos de massas por excelência. Porém, não se pode esquecer, igualmente, o papel dos mass media, ao criar e divulgar novos "heróis" e ao interessar-se pelas suas vidas. Isto verifica-se não só no mundo do desporto, do cinema e da arte, como no do próprio empresariado, sobretudo o de sucesso, que aparece assim como o descendente mais direto da "burguesia conquistadora" oitocentista, para utilizar a conhecida expressão de Charles Morazé. ${ }^{15}$

"I AMADO MENDES, José M. A biografia na história. Munda, n. 24, 1992, p. 33-42; O contributo da biografia para o estudo das elites locais: alguns exemplos. Anńlise Social, v. 27 , n. $116-117,1992\left(2^{p}\right.$ e $\left.3^{\circ}\right)$, p. 375-385,

12 A designação aparece, por exemplo, numa interessante série sobre o nosso século, produzida pela BBC, a qual começou a ser transmitida em Portugal, pela SIC, em 26 de setembro de 1996.

13 Las individualidades en la Historia. Actas de las II Conversaciones Internacionales de Historia. Universidade de Navarra (Pamplona, 21-23 mar. 1979), ed. dir. por V. Vásquez de Prada et al., Pamplona: Ed. Universidade de Navarra, 1985.

14 Problèmes et mèthodes de la biographie. Actes du Colloque. Sorbonne 3-4 mai 1985, Paris: Publ. de la Sorbonne/Histoire du Present, 1985.

is MOZARÉ, Charles. Os burgueses à conquista do mundo, 1780-1895 v. 12 de Rumos do mundo (trad. do francês). Lisboa: Cosmos, 1965. 
Se, em termos teóricos e metodológicos, a biografia não provoca, hoje, tantas reticências como algumas décadas atrás, não é menos verdade que, do ponto de vista prático, os resultados são menos lisonjeiros. No que se refere aos historiadores propriamente ditos, tem-se privilegiado o estudo de alguns dos consagrados aos quais se tem dedicado colóquios, congressos ou obras, mais ou menos desenvolvidos -, permanecendo a vida e obra de muitos outros ainda na sombra. Para me referir apenas ao caso português - que me é mais familiar -, basta recordar os nomes de A. Herculano, Rebelo da Silva, Oliveira Martins ou mesmo Alberto Sampaio e Martins Sarmento, cuja biografia tem merecido certa atenção, ao invés do que sucede com muitos outros, ainda relativamente esquecidos (Fidelino de Figueiredo, Paulo Merêa, Damião Peres, Virgínia Rau, Borges de Macedo, Joaquim Barradas de Carvalho, etc., para me reportar apenas a alguns dos já falecidos).

Mesmo assim, daquilo que se sabe sobre esses e outros historiadores não mencionados, pode admitir-se, pelo menos como hipótese de trabalho, que a formação inicial de vários deles ajuda a explicar, pelo menos em parte, o tipo de História a que, de preferência, se dedicaram e, inclusive, a metodologia que utilizaram. Por exemplo, enquanto matemáticos, como Luciano Pereira da Silva ou Luís de Albuquerque, se destacaram na História da náutica e das viagens de exploração marítimas, outros, de formação jurídica - como Paulo Merêa, Marcello Caetano ou Guilherme Braga da Cruz - interessaram-se, sobretudo, pela História do direito ou pela História político-institucional. Há que prosseguir os estudos, procurando detectar nexos compreensíveis - ou eventuais desvios, algo surpreendentes - entre pontos de partida (formação, experiências, vivência, etc.) e pontos de chegada (o tipo de História produzido).

Menos desenvolvida ainda que a biografia - ou melhor, a "nova biografia", pois a biografia tradicional, de índole apologética, remonta, pelo menos, à hagiografia medieval - está a própria prosopografia. Esta, segundo J. Andreau, "consiste em estabelecer notícias biográficas individuais e em as confrontar. Ao invés da biografia, ela não se aplica a um só homem [ou mulher, dever-se-á acrescentar], considerado interessante, mas a vários, a uma amostra - cuja importância e composição resultam da documentação disponível e que se supõe representativa do grupo estudado"."

${ }^{16}$ ANDREAU. J. Prosopographie. In: BURGUIÈRE, André (ed.). Dictionnaire des sciences historiques. Paris: PUF, 1986, p. 516-548. 
Como escreveram L. Bergeron e G. Chaussinand-Nogared, "tratase, a partir das personalidades, de preparar a 'definição de tipos', de fazer ressaltar os traços comuns e as diferenças - a partir do singular, fazer do "singular plural"."."

No caso dos historiadores propriamente ditos, entre outros podiam ser estudados grupos como os seguintes: docentes universitários que, por inerência das funções exercidas, são simultaneamente investigadores; historiadores locais, freqüentemente amadores, privilegiando a erudição e a História factual e cronológica; arquivistas, cuja investigação se centra fundamentalmente na exploração e divulgação de fontes inéditas; diplomatas que, com conhecimento do ofício, se dedicam à História diplomática, embora nem sempre devidamente inserida na História geral; historiadores influenciados, predominantemente, por determinada historiografia (francesa e/ou inglesa, por exemplo); investigadores que têm vindo a interessar-se por novos "objectos da História", como a História das mulheres, a História empresarial, a cultura de empresa - ou, em inglês, "corporate culture" -, a Arqueologia e o patrimônio industriais e o quotidiano. Além de algo já se ter feito nestes domínios, convirá, através da constituição de equipes interregionais, encorajar e estimular a exploração do estudo destas e de outras temáticas, ainda praticamente desconhecidas."

Por último, a autobiografia ou, tratando-se de historiadores, a chamada Ego-história. Tradicionalmente, os historiadores, à exceção de uma ou outra entrevista de circunstância, pouco falavam de si próprios. Declara-o, de forma muito categórica, Réne Rémond (já anteriormente citado, com o diretor da obra Etre historien anjourd'hui), ao sublinhar:

"Os historiadores não estão treinados para falarem de si próprios: conhecem-se muitos que tenham redigido as suas memórias?"

Contudo, a situação vai-se alterando lentamente, como revela o livro já acima referido, Ensaios de Ego-história, no qual foi possível reunir testemunhos pessoais de alguns historiadores franceses de maior renome. A propósito deste novo gênero - a Ego-história -, escreveu Pierra Nora, na apresentação do dito trabalho:

"Um gênero novo, para uma nova idade da consciência histórica [recorde-se que a $1^{\sharp}$ ed. data de 1987], que nasce do cruzamento

17 Idem, p. 546.

is Rémond, op. cit., p. 349.

${ }^{19}$ Chaunu et al., op. cit., p. 287. 
de dois grandes movimentos: por um lado, o abalo das referências clássicas da objectividade histórica, por outro, a investigação do presente pelo olhar do historiador. Toda uma tradição científica levou os historiadores, desde há um século, a apagarem-se perante o seu trabalho, a dissimularem a personalidade por detrás das suas fichas, a evadirem-se para uma outra época, a não se exprimirem senão por intermédio de outros, permitindo-se fazer, na dedicatória da tese, no prefácio do ensaio, uma conferência furtiva".

E prossegue o autor:

"A experiência da historiografia pôs em evidência, há uma vintena de anos, os falsos aspectos desta impersonalidade e o caráter precário da sua garantia. Também o historiador dos dias de hoje está pronto, ao contrário dos seus antecessores, a confessar a sua ligação estreita, íntima e pessoal que mantém com o seu trabalho. Ninguém ignora que um interesse confessado e elucidado oferece um abrigo mais seguro do que vagos projectos de objetividade. $\mathrm{O}$ obstáculo transforma-se em vantagem. A explicação e a análise do investimento existencial em vez de afastarem uma investigação serena, tornam-se o instrumento e a alavanca da compreensão".

Dadas as vantagens apontadas por P. Nora - que eu subscrevo na totalidade -, não seria de se criar o hábito de as obras historiográficas, incluindo os manuais escolares, virem acompanhados de elementos biobibliográficos sobre os respectivos autores, a exemplo do que já se faz, embora de modo demasiado sucinto, em algumas coleções ou publicações?

Em Portugal, embora ainda não disponhamos duma obra do gênero da indicada, podem extrair-se elementos úteis para a compreensão do percurso biográfico de alguns historiadores em depoimentos dos próprios, já publicados. ${ }^{21}$

Como se infere do que fica exposto, a História - ou, em sentido mais alto, a própria história da História - não pode ser devidamente compreendida se não se atender, quer ao respectivo contexto, quer ao seu artífice, isto é, ao historiador. Quanto ao primei-

20) Chaunu et al., idem, p. 9 .

${ }^{21}$ Na revista Ler História, sob a rubrica "Ofício de Historiador", foram publicados depoimentos dos seguintes historiadores portugueses: A. H. de Oliveira Marques, José Augusto França, Luís de Albuquerque e Vítor de Sá (n. 14, 1988, p. 126-132); António Manuel Hespanha, Joaquim Veríssimo Serrāo, Luís Reis Torgal e Maria Filomena Mónica (n. 16, 1989, p. 137-145); António Pedro Vicente, José Mattoso, Manuel Villaverde Cabral, Miriam Halpern Pereira e Sacuntala de Miranda (n. 17, 1989, p. 137-151). Trata-se de testemunhos com interesse, mas o seu número (apenas 13) é diminuto, face, por exemplo, aos 651 inventariados no Repertório Bibliográfico da História Portuguesa. 1974-1994 (Coimbra, 1995). 
ro aspecto, ja foi destacado por Georg G. Iggers, num interessante e útil livro, sob o título New directions in European History (publicado em 1975 e reeditado em 1985):

"A história da História nunca pode ser compreendida em termos de desenvolvimento interno da disciplina, já que ela reflete o contexto social, político e institucional em que ela é escrita". ${ }^{22}$

Quanto ao segundo, inferência análoga se pode fazer da seguinte afirmação do mesmo autor: "A função do historiador continua a ser a de reconstruir e interpretar um passado real." ${ }^{, 23}$ Assim sendo, a História, enquanto Ciência ou ramo do saber, também não pode ser adequadamente entendida se não a ligarmos a quem lhe deu origem, o historiador.

Pode ainda acrescentar-se que a função do historiador adquire relevância, à luz da própria função desempenhada pela História, já que é aquele que a torna possível. Sobre o assunto, já se destacou: "Se a História desempenha um papel fundamental na visão que, no decorrer dos séculos, cada sociedade cria dela própria e dos outros, cada historiador, que dá a sua contribuição a essa representação, anda na fronteira estreita entre a construção do mito e a desmitificação. Para melhor explorar este domínio, no qual a parte da subjetividade permanece central, parece essencial desenvolver a 'história da História', encorajando a pesquisa historiográfica". ${ }^{24}$

Por último, e em tom deliberadamente provocatório, poderse-ia perguntar:

\section{Não será toda a história autobiográfica?}

Responder afirmativamente à pergunta, sem matizar a resposta, seria incorrer numa generalização excessiva. $\mathrm{O}$ historiador, como qualquer outro cientista, deverá pautar-se, sempre, por critérios de rigor e de objetividade - na medida em que tal the seja possível -, fundamentando-se nos testemunhos, após terem sido submetidos a apurada e meticulosa crítica. Todavia, dado que, como vimos já, a História é constituída pelo binômio fontes + elaboração/interpretação do historiador, é perfeitamente natural que a obra historiográfica - ou mesmo a História, em geral, para além

\footnotetext{
IGGERS, Georg G. New directions in European History, Londres: Methuen, 1985, p. 5-6.

Iggers, idem. p. 5 .

Rémond, op. cit. p. 350.
} 
da sua forma escrita - denuncie algumas características do respectivo autor.

Em alguns casos, as informações são dadas explícita e deliberadamente pelos próprios historiadores (no prefácio ou introdução a uma obra, ou mesmo no próprio texto). Noutras, mais freqüentes, a informação encontra-se implícita, sendo necessário ler nas entrelinhas ou até mesmo saber interpretar as omissões. Por exemplo, posições de natureza ideológica são suscetíveis de serem detectadas por esta última via.

Vejamos alguns exemplos do primeiro tipo, fornecidos pelos próprios autores. A historiadora francesa Michelle Perrot elegeu como temáticas de parte considerável da sua investigação o movimento operário e a história das mulheres. Como explicar tais preferências? Esclarece a própria autora: "A minha escolha pela história operária não tinha, todavia, nada de fortuito, e a minha evolução posterior ia transformar-se em opção fundamental". ${ }^{25}$ Após explicar como o contexto dos anos 1950 - classe operária, PCF que encarnava, a seus olhos, o "partido da classe operária", etc. - escreve M. Perrot: "A minha ocasião de fazer história operária enraíza-se naquela conjuntura, que explica também a tentativa. À falta do compromisso físico [a autora recorda o desejo de alguns intelectuais trabalharem em fábricas, e os padres operários, ao que eu acrescentaria a experiência do nosso Antero de Quental, como tipógrafo, em Paris, 1866-67] ou diretamente político, tomar a classe operária como objeto da minha investigação parecia-me uma forma de me juntar a ela, ou de a servir, contribuindo para o seu reconhecimento". Mas acrescenta a autora: "Bem entendido, era em grande parte uma ilusão. Até uma data recente - esta terceira revolução industrial em que morre a fábrica clássica tornada local arqueológico e, de repente, bela -, a classe operária interessou-se muito pouco pelo seu passado, parada de lutas entre sindicatos e partidos que, de celebrações em comemorações, lhe construíram uma memória, equivalente à história de França das nossas escolas para a consciência nacional". "Como é sabido, a principal obra de Michelle Perrot sobre o movimento operário tem por título Les ouvriers en grève. France 1871-1890, em dois tomos, que constitui a sua tese de doutoramento (defendida em 1971 e publicada em 1974-75). ${ }^{27}$

Chaunu et al., op, cit., p. 273.

Chaunu et al., op. cit., p. 280.

${ }^{27}$ Utilizei: t. 1, Service de Reproduction des Thèses, Université de Lille III, 1975; t. II, Paris, Mouton, 1974. 
Por sua vez, acerca da História no feminino, a outra temática a que M. Perrot tem dedicado parte da sua investigação, é a própria a elucida-nos acerca dessa sua preferência:

"Dessa educaçăo tipicamente feminina à qual a dimensão religiosa apenas juntou força suplementar - mas a religião é o húmus de todas as educações femininas -, nunca me libertei verdadeiramente: ela moldou-me de forma duradoura, pesou nas minhas escolhas intelectuais e nas minhas condutas sociais. Marcou a História que fiz, mesmo que a tenha feito contra ela. Mas precisei de bastante tempo pare discernir as suas raízes e mecanismos; para compreender sobretudo que há ${ }^{28}$ uma história comum às mulheres e que a relação dos sexos é uma estrutura elementar da História. De tudo isto, estou devedora para com o movimento das mulheres, esta realidade contemporânea multiforme, que ultrapassa infinitamente as organizações formais".

Apresentarei apenas mais dois exemplos de declarações autobiográficas, feitas pelos autores, desta vez de portugueses. Refiro-me, concretamente, a Ezequiel de Campos (1874-1965) e a José Nascimento Ferreira Dias (1900-1926). Ambos foram engenheiros e autores de obra notável, tanto a nível profissional como bibliográfico. Nos seus escritos, defenderam intransigentemente a industrialização e a eletrificação do país. Mas, mais do que isso, no livro de J. Ferreira Dias - Linha de rumo (1945) -, simultaneamente como uma clarividente crítica à política de desenvolvimento até então adotada, apresentam-se linhas definidoras de uma esclarecida estratégia de desenvolvimento, a qual ainda mantém muito de atualizado.

Ora, como é bom de ver, a formação e o exercício da atividade de engenharia moldaram, em grande parte, as suas obras, inclusive de caráter historiográfico. Por sua vez, a leitura dessas não deixa grandes dúvidas de que lhes está subjacente um profundo conhecimento técnico do ramo, adquirido nos bancos da universidade e no exercício da profissão. Mas, não menos interessante, é o fato de, quer um quer outro, terem mencionado determinadas vivências como motivadoras da sua opção pela engenharia. Atentemos, pois, nas suas declarações:

Ezequiel de Campos:

"Nasci, faz hoje [12.12.1944] 70 anos, numa aldeia da região do Minho. A origem, a cultura e o pequeno mundo que me cercava, me

${ }^{28}$ No texto, certamente por lapso, encontra-se "é".

${ }^{29}$ Chaunu et al., op. cit., p. 285-286. 
levaram uma noite, sendo estudante do Liceu, à central elétrica que funcionava nas traseiras do Ateneu Comercial do Porto, entre a Rua de Passos Manuel e a de Santo Antônio: desejei então ser engenheiro. Expresso aqui a minha gratidão à memória do senhor José Antônio de Sousa Basto, que me ajudou a concluir a carreira da antiga Academia Politécnica do Porto". ${ }^{30}$

\section{J. N. Ferreira Dias, por seu turno, confessou:}

"Filho de um ferroviário, cujo exemplo de amor à profissão procuro seguir, desde os 15 anos me eram familiares a saída do comboio 15 , a passagem do 51 ou o atraso do 206; e, a partir dessa idade, nasceu em mim uma afeição enorme que ainda hoje se mantém: observar uma locomotiva. Terminado o Liceu, matriculei-me em engenharia sem um minuto de reflexão ou dúvida, como se a arte de engenheiro fosse o único saber que merecesse o trabalho de ser estudado"."

Como referi anteriormente, mais difícil se torna vislumbrar concepções ou tendências quando não há declarações expressas, como freqüentemente sucede, por exemplo, tratando-se de fatores de caráter ideológico. No entanto, mesmo aqui há que fazer um esforço, especialmente grande quando se trata de obras utilizadas no ensino, como manuais ou simplesmente de consulta. É que, quanto mais completo for o nosso conhecimento dos quadros ideológicos em que se movimentam os autores dos textos a utilizar, mais fácil será reduzirmos a carga ideológica no processo de ensino-aprendizagem ou, pelo menos, tomarmos consciência e explicitarmos a(s) ideologia(s) implícitas e/ou explícitas.

Trata-se de uma necessidade, particularmente numa altura em que nos podemos interrogar se todo o ensino não será ele próprio ideológico, podendo todas as matérias ser postas em causa. A propósito, sublinha Olivier Reboul, na obra L'endoctrinement (1977):

"De repente, todas as matérias de ensino são postas em causa. Reprovar-se-á História o ignorar a luta de classes e menosprezar as culturas aniquiladas pelo colonialismo; à Filosofia o cultivar um ecletismo desmobilizador; à Literatura o censurar as obras contestatórias ou revolucionárias; à Gramática o impor o vocabulário e a sintaxe da classe dominante. Analisam-se minunciosamente os manuais

30. AMADO MENDES, José. Portugal agrícola o industrial? Contornos de una polêmica y sus repercusiones en el desarrollo (siglos XIX-XX). Studia Historica. Historia Contemporanea [Universidade de Salamanca], v. 12, 1994, p. 251.

"Amado Mendes, idem, p. 252. 
escolares para os libertar de tudo o que eles contenham de ideologia".

Essa questão está também relacionada com a problemática dos valores, da qual nem autores, nem obras, nem o próprio ensino se deverão, obviamente, alhear. Embora hoje raramente referido, continuo a julgar válido o princípio segundo o qual informação e formação devem seguir sempre de mãos dadas.

Para concluir, apenas acrescentarei que o percurso biográfico do autor e as respectivas transformações que se vão operando poderão ajudar a compreender a evolução verificada na respectiva obra e vice-versa. Para, mais uma vez, me servir de exemplos portugueses, recordo os casos de Antônio José Saraiva ou, embora de forma menos nítida, de Jorge Borges de Macedo ou de Joaquim Veríssimo Serrão. ${ }^{33}$

Como síntese de tudo o que se acaba de expor, poder-se-ia afirmar: Entre a História e o historiador existem relações - uma "inevitável cumplicidade", como consta do título -, pelo que, um conhecimento mais completo e aprofundado daquela não pode prescindir do aprofundamento da investigação, no que se refere a este.

${ }^{32}$ REBOUL, Olivier. L'endoctrinement. Paris: PUF, 1977, p. 174.

${ }^{33}$ Para mais elementos sobre o assunto, ver Torgal, Amado Mendes e Catroga. História da História, cit., passim. 